\title{
SEAFEM: Herramienta computacional para la determinación de causas de falla en elementos mecánicos metálicos
}

\section{SEAFEM: A computational tool for the determination of failure causes in metallic mechanical components}

\author{
V. Jacobo-Armendáriz, A. Ortiz-Prado y R. Schouwenaars-Franssens \\ Departamento de Ingeniería Mecánica \\ Facultad de Ingeniería, UNAM \\ E-mails:vjacobo@dgapa.unam.mx,armando@servidor.unam.mx,raf_schouwenaars@yahoo.com
}

(Recibido: agosto de 2006; aceptado: febrero de 2007)

\begin{abstract}
Resumen
En respuesta a la problemática nacional acerca de la escasez de expertos en análisis de falla de elementos mecánicos metálicos, se desarrolló en la Unidad de Investigación y Asistencia Técnica en Materiales de la Facultad de Ingeniería de la UNAM, un sistema experto híbrido (SEAFEM) para análisis de falla de este tipo de elementos (engranes, ejes, resortes, cojinetes, entre otros). Esta herramienta de tipo colega, permite por un lado, encaminar al usuario a la determinación de las causas de falla, y a su vez, capacitar personal a través de su uso.

El programa funciona de forma interactiva, plantea preguntas que tendrán que ser contestadas por el usuario y lo encamina hacia la solución del problema. Lo novedoso de este sistema, es el empleo de dos métodos de razonamiento (basado en reglas y basado en casos), lo cual representa una ventaja respecto de otros anteriormente desarrollados, ya que permite al usuario utilizar y ejercitar sus procesos de razonamiento deductivo y el manejo de información estructurada en bases de datos. Éste es un proceso similar al que realiza un experto, ya que establece un proceso metodológico en la solución del problema y utiliza el conocimiento de otros casos que ha resuelto o que se reportan en la literatura. En este artículo, se presenta la metodología de desarrollo del SEAFEM, su estructura de conocimiento, funcionamiento y la aplicación en la solución de problemas de análisis de falla en ejes y barras de torsión.
\end{abstract}

Descriptores: Análisis de falla, metalurgia mecánica, sistemas expertos, inteligencia arti fi cial, razonamiento basado en casos, razonamiento basado en reglas.

\footnotetext{
Abstract

A hy brid ex pert sys tem for fail ure anal y sis of me tal lic me chan ical com pounds was de vel oped by the group for tech nical as sis tance and materials re search of the de partment of me chan ical en gi neer ing of the UNAM, to pro vide a way of com pen sat ing the lack of ex perts in this field. This ex pert sys tem (SEAFEM) anal y ses com ponents such as gears, shafts, springs and bear ings. It is also a tool to train peo ple through its use by direct ing the inexperienced user to ward the de ter mina tion of a fail uremech anism trough an in ter ac tive con fig u ra tion and a set of log ically or dered ques tions. The in no va tive as pect of the sys tem resides in the us age of two clas sical log ical schemes (Rule Based Rea soning and Case Based Rea soning), which is ad van ta geous com pared
} 
SEAFEM: Herramienta computacional para la determinación de causas de falla en ...

\begin{abstract}
sys tems de vel oped by other groups as a prac tice of de duc tive rea son ing pro cess and structured in for mation management is com bined. The methodem ployed here is sim $i$ lar to that fol lowed by an ex pert which fol lows a log ical struc ture of problemanal ysis com bined with ex perience based on pre viously stud ied cases.

This paperexplains the functioning, knowledgestructureandap plica tion to thesolut tion offail ure problems in shafts and tor sion bars, to gether with an ex pla na tion of the systemdevelopment.
\end{abstract}

Keywords:Fail ureanalysis, mechanicalmetallurgy, expertsystems, artificial intet ligence, case based rea son ing, rule based rea soning.

\section{Introducción}

Cuando ocurre una falla en un elemento mecánico se debe realizar un análisis minucioso (aplicación del método científico) para determinar su causa (diseño inapropiado, deficiencias del material, problemas de manufactura, condiciones de servicio fuera de especificación, mantenimiento inadecuado, etc.). Este proceso se conoce como análisis de falla (AF). Una vez que la causa es determinada, deben tomarse medidas correctivas para prevenir recurrencias futu- ras. Los expertos en esta área examinan toda la información sobre el caso, establecen hipó- tesis y desarrollan procedimientos para comprobarlas.

Sobre el proceso de análisis se puede comentar que dependiendo de la naturaleza de la falla, varia la profundidad del estudio y la secuencia de investigación para identificar las diferentes causas que la provocan. Los procesos de examen siguen una serie de etapas (Metals Handbook, 1990) y los resultados en cada una determinan la manera en la cual proceden las siguientes fases. Con base en la información obtenida en cada etapa, es posible a partir de un aspecto simple de la investigación, plantear hipótesis sobre los mecanismos de falla como puede ser la inspección visual de una superficie fracturada.

El AF es un tema complejo e involucra diferentes campos del conocimiento tales como mecánica, metalurgia, química y electroquímica, procesos de manufactura, análisis de esfuerzos, diseño y mecánica de la fractura. Es muy difícil que una persona sea experta en todos estos campos, por lo que la determinación de la causa de una falla mayor, usualmente requiere un equipo de expertos. Esto normalmente toma años de entrenamiento formal, seguido por años de experiencia práctica. Para los casos en donde la información es escasa o ambigua, la revisión de problemas similares reportados en la literatura (Corrosion Atlas, 1991; Heyes, 1998; Jones, 1998; Metals Handbook, 1990 y Naumann, 1983), es una tarea valiosa, la cual permite obtener pistas para acercarse a la solución.

Los expertos en $\mathrm{AF}$, en general, son escasos en el mundo. En México, existen centros de desarrollo, consultores especializados y universidades como la UNAM, en donde la industria puede obtener apoyo en esta área. Sin embargo, la demanda de estos servicios no es cubierta en su totalidad, ya que existe un amplio sector de la industria que lo requiere. Se puede señalar que en la empresa nacional no existe una cultura del AF; actualmente en la práctica, si una pieza sufre daño o deterioro, debe repararse en el menor tiempo posible. Cuando las fallas se presentan con frecuencia relativa, lo más común es modificar la parte o sistema a partir de la percepción particular del técnico encargado, por lo que al corregir el problema, lo 


\section{Jacobo-Armendáriz, A. Ortiz-Prado y R. Schouw enaars-Franssens}

convierte en procedimiento común. En algunas ocasiones, las empresas se deciden por contactar a expertos en AF, incurriendo en inconvenientes de costos, mismos que se reducirían si se contara con personal capacitado en el área. En muy pocos casos, existen ingenieros en la empresa con la experiencia para realizar AF de un sistema o componente. Por consecuencia, es necesario contar con una mayor cantidad de expertos.

Como respuesta a este problema, en el mundo se ha tenido especial interés en desarrollar sistemas computarizados para capacitar personal o para apoyar a los expertos. Uno de los objetivos que se persiguen es preservar el conocimiento, el cual se puede perder si los responsables se retiran de sus trabajos. En ese sentido, se han realizado algunas aplicaciones basadas en el conocimiento, principalmente sistemas expertos (SE). Estos sistemas no han sido comercializados y solo se han empleado para educación e investigación. Los sistemas más importantes se han construido usando la técnica de razonamiento, basado en casos (RBC); Liao et al. (1999) de la Universidad de Louisiana, elaboraron un sistema para la identificación de mecanismos de falla; GrahamJones y Mellor (1997) de la Universidad de Southampton, presentan un sistema orientado a resolver problemas para elementos mecánicos que permite realizar AF antes y después de la ocurrencia del problema; por su parte, Robergeet al. (1996), desarrollaron un sistema específico para fallas por corrosión. Asimismo, existen sistemas expertos para áreas específicas de $\mathrm{AF}$, tales como análisis fractográfico, fallas en rodamientos, fallas en concreto, diagnóstico de defectos en neumáticos, fallas en soldaduras, etc.

Considerando la problemática y necesidad descrita, se desarrolló en la Unidad de Investigación y Asistencia Técnica en Materiales (UDIATEM) de la Facultad de Inge- niería de la UNAM, un SE en AF de elementos mecánicos metálicos, capaz de identificar las causas de falla de componentes mecánicos. Este sistema tiene como principal orientación la docencia y puede ser empleado en la solución de problemas convencionales. En la solución de casos, actúa como un colega, lo que permite que el usuario (ingeniero o estudiante de ingeniería mecánica), con un nivel de conocimientos básicos de ciencia de materiales, metalurgia física y mecánica, incremente paulatinamente su nivel de experiencia al utilizar gradualmente el programa. El SE funciona de forma didáctica para poder instruir a nuevos usuarios en el tema del $\mathrm{AF}$, debido a que es una herramienta interactiva, en donde el sistema plantea preguntas que tendrán que ser contestadas por el usuario y lo encamina hacia la solución del problema. Al manejar dos métodos: Razonamiento basado en reglas (RBR) y RBC, el sistema presenta una ventaja respecto de otros, los cuales básicamente utilizan el RBR, ya que permite al usuario utilizar y ejercitar sus procesos de razonamiento deductivo y por otro lado el manejo de información estructurada en bases de datos, lo cual es un proceso similar al que realiza un experto, ya que éste establece un proceso metodológico para solucionar problemas y utiliza el conocimiento de otros casos que se han resuelto, así como de los que se reportan en la literatura.

\section{Metodología de desarrollo del SEAFEM}

En primer instancia se evaluó la factibilidad para el desarrollo del SE en AF empleando para esto el procedimiento propuesto por Beckman (1991). Con base en el resultado positivo de esta evaluación, se estructuró la forma en que se debería desarrollar el sistema (Cerrud, 2002; Jacobo et a.l, 2003), se estudiaron los diferentes enfoques de grupos de investigación que se han desarrollado o se 
SEAFEM: Herramienta computacional para la determinación de causas de falla en ...

encuentran trabajando en sistemas similares (Graham y Mellor, 1995a, 1995b, 1997a, 1997c; Kazaz, 2003; Komai et al., 1995; Lee, 2001; Liao et al., 1999a, 1999b; Liao, 2000, 2004; Menandro et al., 1995; Roberge et al., 1996). Asimismo, se consideraron los resultados emanados por Shu-Hsien (2005), el cual revisó las metodologías para el desarrollo de SE's aplicadas en el período 1995-2004. Por otra parte, se analizó la bibliografía sobre AF (Brooks y Choudhury, 1993; Cerrud et al., 2002; Das, 1996 y Lange, 1998) con el fin de aportar elementos para la investigación y con el objetivo de definir en forma sistemática las fallas de elementos mecánicos. Con base en lo anterior, se estableció el marco de referencia para el proyecto.

Posteriormente, fue realizado un proceso de capacitación en donde se estudiaron los conceptos sobre SEs, principalmente en las metodologías para la adquisición y representación del conocimiento, se integró un grupo de expertos, tomando en cuenta nivel de experiencia, disposición y disponibilidad de tiempo para involucrarse en las entrevistas. En la determinación de las características de operación participaron expertos en AF, ingenieros del conocimiento y los usuarios potenciales. Las consideraciones que se tomaron en cuenta fueron ambiente de interacción con el usuario, etapas de solución de un problema, definición del tratamiento de la incertidumbre, estructuración en módulos, plataforma computacional, limitaciones del usuario y características de la base de conocimientos.

Con las experiencias obtenidas en el desarrollo de este sistema se identificaron los inconvenientes que se presentan en el modelado del conocimiento de los expertos, en particular lo relacionado con las fases de adquisición y representación del conocimiento (Cerrud et al., 2000). Se establecieron estrategias para la adquisición del cono- cimiento definiendo técnicas para la obtención de información como entrevistas o sesiones. Se aplicaron diagramas de causa efecto, ya que en un problema de AF los efectos son conocidos y se tiene como objetivo determinar las causas que condujeron a la falla. Con esto se logró definir el método de análisis de los expertos y la forma en que realizan su razonamiento, asimismo, se determinaron las estructuras de representación del conocimiento, definiéndose las de reglas de decisión y los marcos para la descripción de los casos.

En el caso del módulo de RBR para seleccionar el shell, se aplicó una matriz de decisión; los criterios que se evaluaron fueron costo, mecanismos de adquisición del conocimiento, interfases externas, reportes generados, calidad de la documentación, facilidad de aprendizaje, facilidad de uso, requerimientos de hardware, soporte técnico y características generales. El shell que resultó seleccionado fue Visual Rule Studio, el cual trabaja dentro de la plataforma de Visual Basic. También se llevó a cabo un proceso de aprendizaje del shell, que se utilizó para el desarrollo del sistema. En cuanto al módulo de RBC, este fue desarrollado en la plataforma de Visual Basic. Para la base de conocimientos, se usó Microsoft Access, Excel y editores de imágenes.

Las bases de conocimientos y de casos se integraron a partir de la información obtenida de los expertos y de casos reportados en la literatura. De acuerdo con el orden en que el experto humano realiza la solución de un caso, se determinó la secuencia de operación del sistema. Para observar la interacción de los elementos del sistema se desarrolló y probó un prototipo con una base de conocimientos limitada (Jacobo et al., 2000). Esto tuvo la finalidad de probar las características de operación definidas y llevar a cabo los ajustes correspondientes. Pos- 


\section{Jacobo-Armendáriz, A. Ortiz-Prado y R. Schouw enaars-Franssens}

teriormente, se realizó la expansión del sistema.

El sistema tal como se presenta en este artículo, cuenta ya con un módulo para el AF de ejes (Jacobo et al., 2002, 2004), y un módulo de razonamiento basado en casos (Jacobo et al., 2004; Ortiz et al., 2003). Es importante mencionar que estos subsistemas están desarrollados sobre la base de una estructura global, la cual está diseñada de tal manera que en un futuro se puedan incorporar nuevos módulos. Se trata pues, de un sistema flexible y con capacidad para ser robustecido. Asimismo, dentro de la estructura queda abierta la posibilidad de incorporar módulos que se pueden desarrollar a futuro, tales como análisis de esfuerzos, deterioro ambiental, propagación de grietas, etc. Finalmente, se realizó el proceso de validación del sistema, el cual se llevó a cabo resolviendo problemas de campo, de los cuales ya se tenía la solución.

\section{Base de conocimientos}

Debido a que las características de las técnicas de RBR y RBC son diferentes, la base de conocimientos tiene una diferente estructura. Por un lado, en RBR se tiene una estructura de reglas, clases y atributos; mientras que el de RBC presenta una organización basada en una estructura de información que contiene registros de la documentación de los casos y sus índices de búsqueda.

\section{Módulo RBR}

El primer bloque de reglas corresponde a la selección del elemento y material, éste es un módulo general, determina el tipo de elemento que se desea analizar y el material del que está compuesto. El segundo bloque sirve para determinar el tipo de falla que se presentó. La fractura es el tipo de falla más común en ejes, de tal forma que este módulo sólo funciona para fractura; posteriormente, se expandirá la base de conocimiento hacia otros tipos de fallas, en esencia ésta es la parte fundamental de la base de conocimiento en la fase de inspección visual, y por ende, es el módulo con mayor número de reglas. Como parte de este módulo se encuentra un grupo de reglas que sirve para corroborar el tipo de carga y fractura, así como las conclusiones intermedias. El tercer bloque tiene como función recomendar las pruebas mecánicas necesarias para elevar el nivel de confianza de las conclusiones realizadas por el sistema o para descartarlas; por esta razón, la información sobre los resultados de pruebas mecánicas es fundamental para que el sistema pueda mostrar las conclusiones en pantalla. El cuarto bloque sirve para asignar la dureza a los materiales respecto a sus propiedades teóricas y poder hacer comparaciones de estos datos con los obtenidos en el laboratorio.

Después de la determinación del tipo de falla (por fatiga, frágil, dúctil) se procede a determinar las pruebas de laboratorio que se requieren realizar para tener más elementos que permitan validar las conclusiones obtenidas de la inspección visual de la pieza.

Con el resultado de las pruebas realizadas al elemento aunado al tipo de falla, condiciones de operación, ambientales, etc., se determinan las causas que llevaron al elemento a fallar. En el cuadro 1 se muestra un ejemplo de cómo se generaron las reglas a partir de una estructura de clases y atributos. Por otra parte, en la figura 1 se presenta un fragmento del árbol de fallas que se generó para poder definir las reglas. 
DOI: http://dx.doi.org/10.22201/fi.25940732e.2007.08n4.021

SEAFEM: Herramienta computacional para la determinación de causas de falla en ...

Cuadro 1. Clases y atributos en la construcción de reglas

\begin{tabular}{cc}
\hline & Clase: Información del Material \\
\hline Atributos & Variables del atributo \\
Materiales & Acero, Bronce, Acero inoxidable, Latón, Aluminio, \\
Fundiciones. & 1008, 1010, 1020, 1040, 1060, 4140, 4120 \\
Tipo de acero & Bajo, Medio, Alto \\
Porcentaje de carbono & Bajo, Medio, Alto \\
Nivel de aleación & Dúctil, Frágil \\
Comportamiento del material &
\end{tabular}

Si el tipo de acero es 1008 , entonces el porcentaje de carbono es bajo.

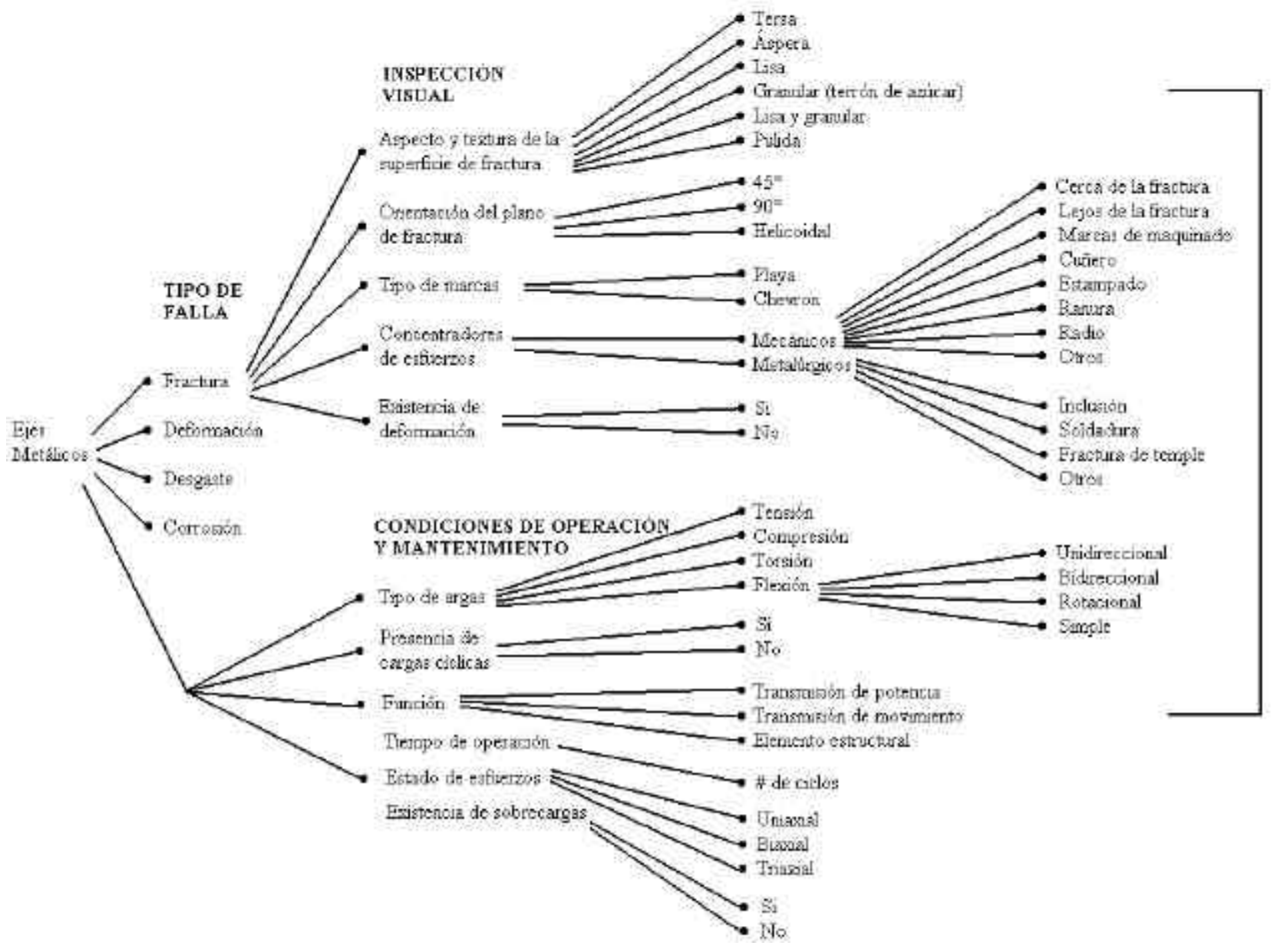

Figura 1. Fragmento del árbol de fallas en ejes para el caso de fallas de fractura 


\section{Módulo RBC}

La base de conocimiento del sistema RBC está integrada por dos principales componentes:

1. Archivos con los índices de similitud para cada caso. Es decir, éstas reúnen los valores lógicos de los atributos.

2. La descripción completa de los casos históricos de problemas de AF con su solución. Ésta contiene los elementos que se muestran en la tabla 1 y también imágenes sobre el problema en estudio.

\section{Operación del sistema}

En su funcionamiento, el sistema tiene la posibilidad de solucionar los problemas con los dos enfoques (RBR y RBC), con la intención de que el usuario tenga más elementos para la solución del problema de AF.
El sistema funciona con la siguiente dinámica (figura 2):

1. Obtención de la información del problema a resolver.

2. Solución de un problema de AF a través de la aplicación del subsistema por reglas.

3. Solución del problema a través de razonamiento basado en casos.

4. Análisis por parte del usuario de las soluciones obtenidas por ambos métodos.

5. Incorporación de los casos resueltos a la base de casos.

Tabla 1. Estructura definitiva de un caso para el sistema $R B C$

\begin{tabular}{|c|c|c|}
\hline & \multicolumn{2}{|c|}{ Título y número de caso } \\
\hline & Clases & Ejemplos de atributos \\
\hline \multirow{6}{*}{ Problema } & Llaves primarias & Marcas de playa, atmósfera marina \\
\hline & Información del material & $\begin{array}{l}\text { Ferroso, no ferroso, contenido de } \\
\text { carbono }\end{array}$ \\
\hline & Características de la superficie de fractura /grieta & Cuellos, patrón de chevron, labios \\
\hline & Observación con estereoscopio /microscopio óptico & $\begin{array}{l}\text { Picaduras, estrías, fractura } \\
\text { intercristalina }\end{array}$ \\
\hline & Exámen químico /Metalografía & $\begin{array}{l}\text { Inclusiones, porosidad, corrosión } \\
\text { intergranular }\end{array}$ \\
\hline & Análisis SEM (Microscopio electrónico de barrido) & Clivaje, microcavidades \\
\hline \multirow{4}{*}{ Solución } & \multicolumn{2}{|c|}{$\begin{array}{l}\text { Descripción del caso incluyendo información del material, características de la superficie de } \\
\text { fractura / grieta, observación con estereoscopio / microscopio óptico, examen químico / } \\
\text { metalografía y análisis SEM. Además se incluyen imágenes. Algunos casos incluyen datos } \\
\text { extras como análisis de esfuerzos o pruebas destructivas. }\end{array}$} \\
\hline & \multicolumn{2}{|c|}{ Discusión y análisis de la información. } \\
\hline & \multicolumn{2}{|l|}{ Causa más probable } \\
\hline & \multicolumn{2}{|l|}{ Acciones correctivas } \\
\hline
\end{tabular}




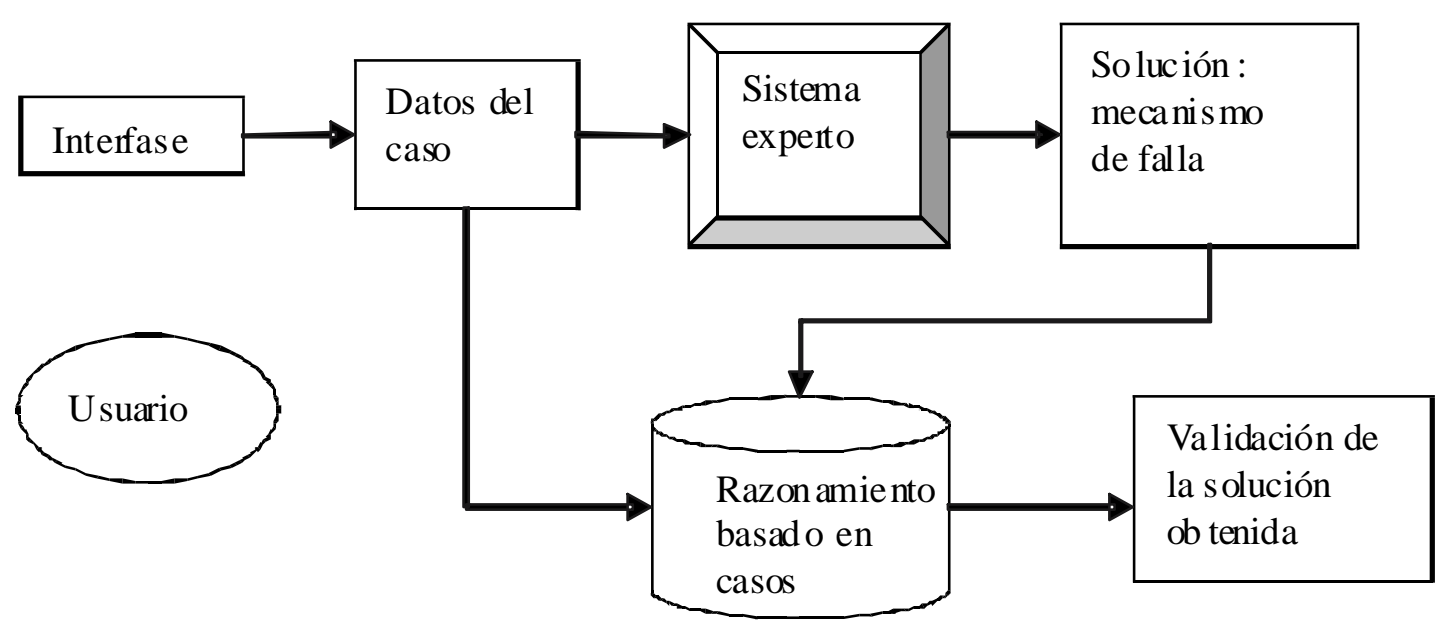

Figura 2. Diagrama de operación del sistema híbrido

En la tabla 2, se muestra la descripción de los pasos genéricos en la solución de un caso:

Tabla 2. Secuencia para la solución de un caso mediante RBR y RBC (Jacobo et al., 2002)

\begin{tabular}{cc}
\hline Paso & Procedimiento \\
\hline 1 & Adquisición de la información del caso. \\
2 & Solución mediante RBR \\
3 & Vinculación simultánea con el Shell. \\
4 & Revaloración continua de la información. \\
5 & Activación y validación de Reglas. \\
6 & Inferencia sobre premisas desconocidas. \\
7 & Procesamiento de información relacionada. \\
8 & Detección de contradicciones entre reglas. \\
9 & Validación por medio de factor de confianza. \\
10 & Solución mediante RBC \\
11 & Confrontación de resultados con entradas. \\
12 & Presentación de conclusiones. \\
\hline
\end{tabular}




\section{Jacobo-Armendáriz, A. Ortiz-Prado y R. Schouw enaars-Franssens}

\section{Operación del módulo de RBR}

Para solucionar un problema de $\mathrm{AF}$, en primera instancia el usuario describe el caso, por lo que interactúa con el sistema, describiendo el tipo de material, tipos de elemento (flechas, engranes, resortes, etc), función (transmisión de potencia, transmisión de movimiento, soporte), modo de falla (fractura, deformación, desgaste, corrosión). Después de esto se plantean otro grupo de preguntas que están ligadas a las respuestas anteriores. Éstas últimas están relacionadas con características físicas, tipos de carga, geometría, morfología y textura de la superficie de fractura y concentradores de esfuerzos, entre otros. Una vez capturada la información relativa a la inspección visual del elemento se desprenden las primeras conclusiones intermedias (mecanismo de falla), después se realiza un análisis del elemento respecto a las cargas a las que estuvo sometido en condiciones normales de operación y como resultado se encuentran los esfuerzos máximos y su orientación. Después de lo anterior, el sistema recomienda la realización de pruebas de laboratorio que sean convenientes para el caso en estudio. La información obtenida de las pruebas se retroalimenta al sistema para con esta información complementaria definir la causa de la falla o en su defecto, si existiese alguna anomalía, revisar las inconsistencias.

El proceso descrito se realiza a través de un formulario general, el cual está constituido por cinco ventanas y una serie de botones de control (Figura 3). La ventana superior izquierda contiene las instrucciones para la captura correcta del formato al momento de cada pregunta o sección. La ventana intermedia del lado izquierdo las preguntas realizadas por el sistema y la inferior izquierda tiene una serie de posibles respuestas presentadas por el sistema. La ventana superior derecha contiene un historial que guarda las preguntas y respuestas correspondientes al caso analizado, ésta fue creada para que el usuario pueda observar de forma rápida las respuestas introducidas al sistema; así como para darle seguimiento al caso en estudio. La ventana inferior izquierda presenta los resultados parciales o finales. En la parte izquierda del formulario se encuentran botones gráficos que dan acceso a los controles básicos. Sobre este formulario aparecen ventanas que ejemplifican algunos conceptos (Figura 4) como superficies de fractura, marcas sobre la superficie, concentradores de esfuerzos, etc. Con la presencia de estos gráficos se pretende eliminar las ambigüedades en la descripción escrita de la geometría de los elementos; también son utilizados para corroborar la información que el usuario ha introducido al sistema, si el usuario definió las características de la superficie de fractura y el tipo de carga, se le presentarán distintas imágenes patrón de las superficies, y deberá escoger la imagen que más se parezca al elemento analizado, con este procedimiento el sistema compara los datos introducidos con la imagen seleccionada.

Después de haber obtenido las primeras conclusiones intermedias (sobre mecanismo de falla por inspección visual), se realiza un análisis del elemento respecto a las cargas a las que estuvo sometido en condiciones normales de operación (Figuras 5 y 6) y como resultado se encuentran los esfuerzos máximos y su orientación. 
SEAFEM: Herramienta computacional para la determinación de causas de falla en ...

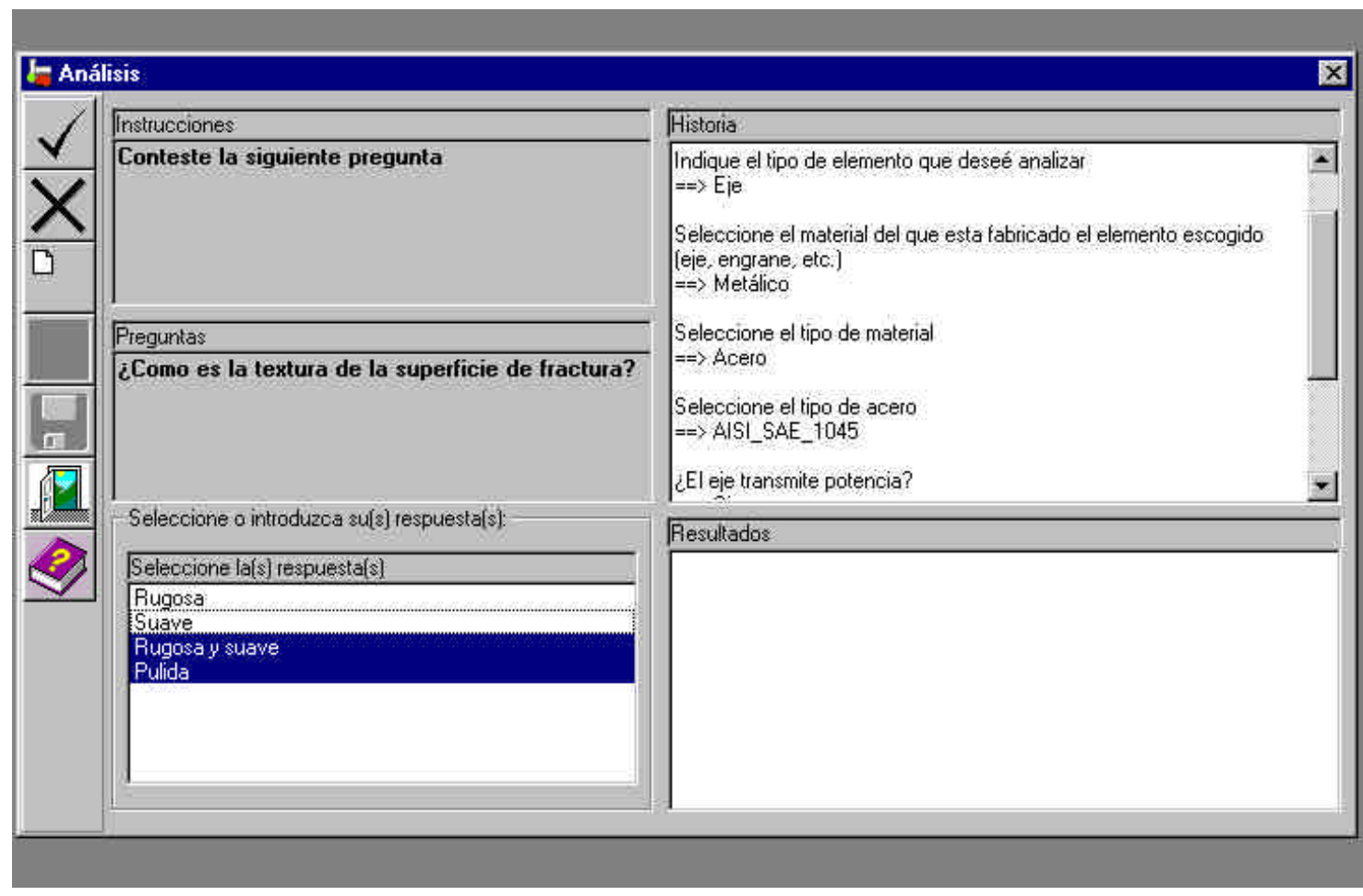

Figura 3. Formulario general

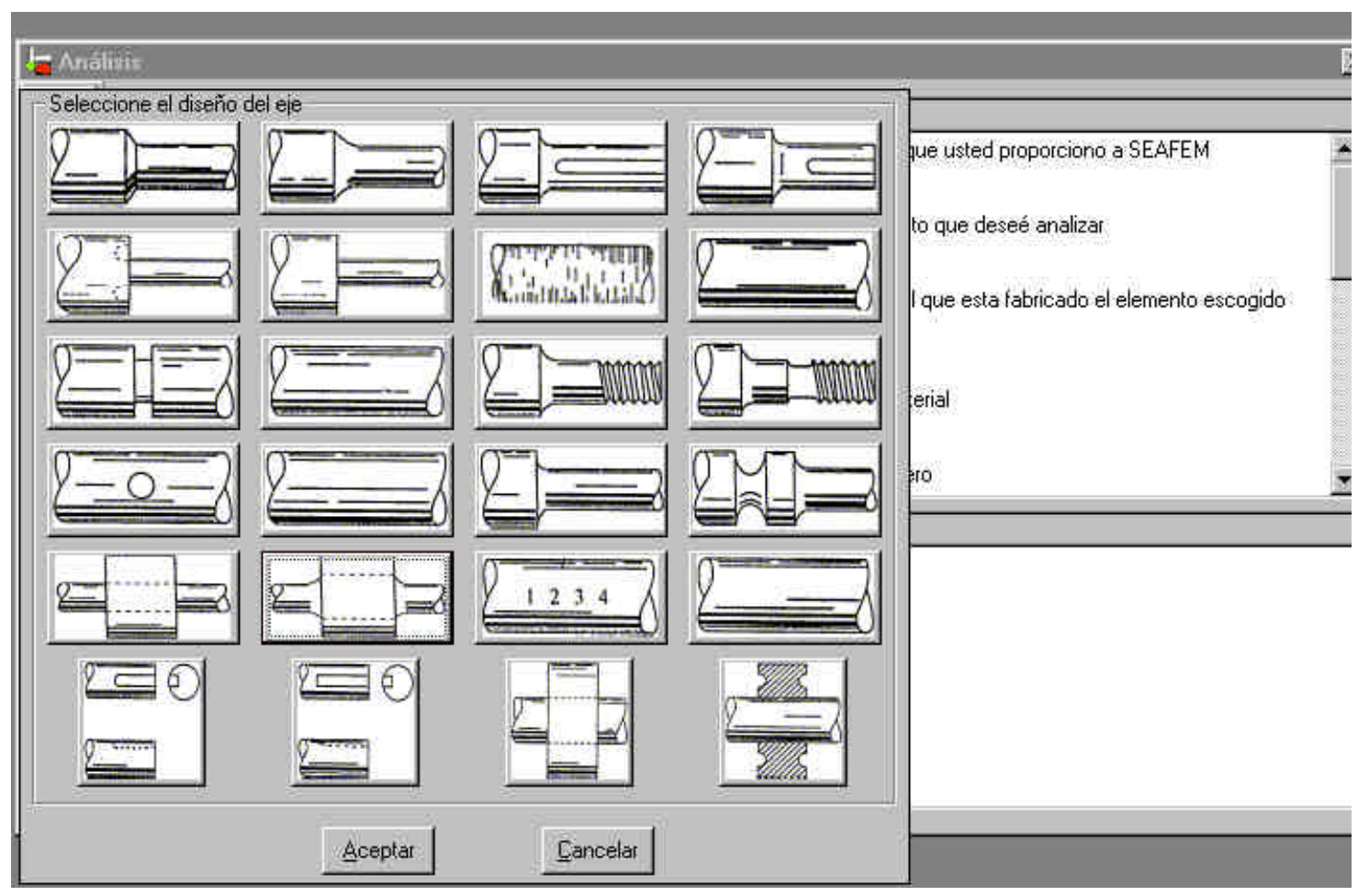

Figura 4. Ventana para "gráficos ejemplo" 


\section{Jacobo-Armendáriz, A. Ortiz-Prado y R. Schouw enaars-Franssens}

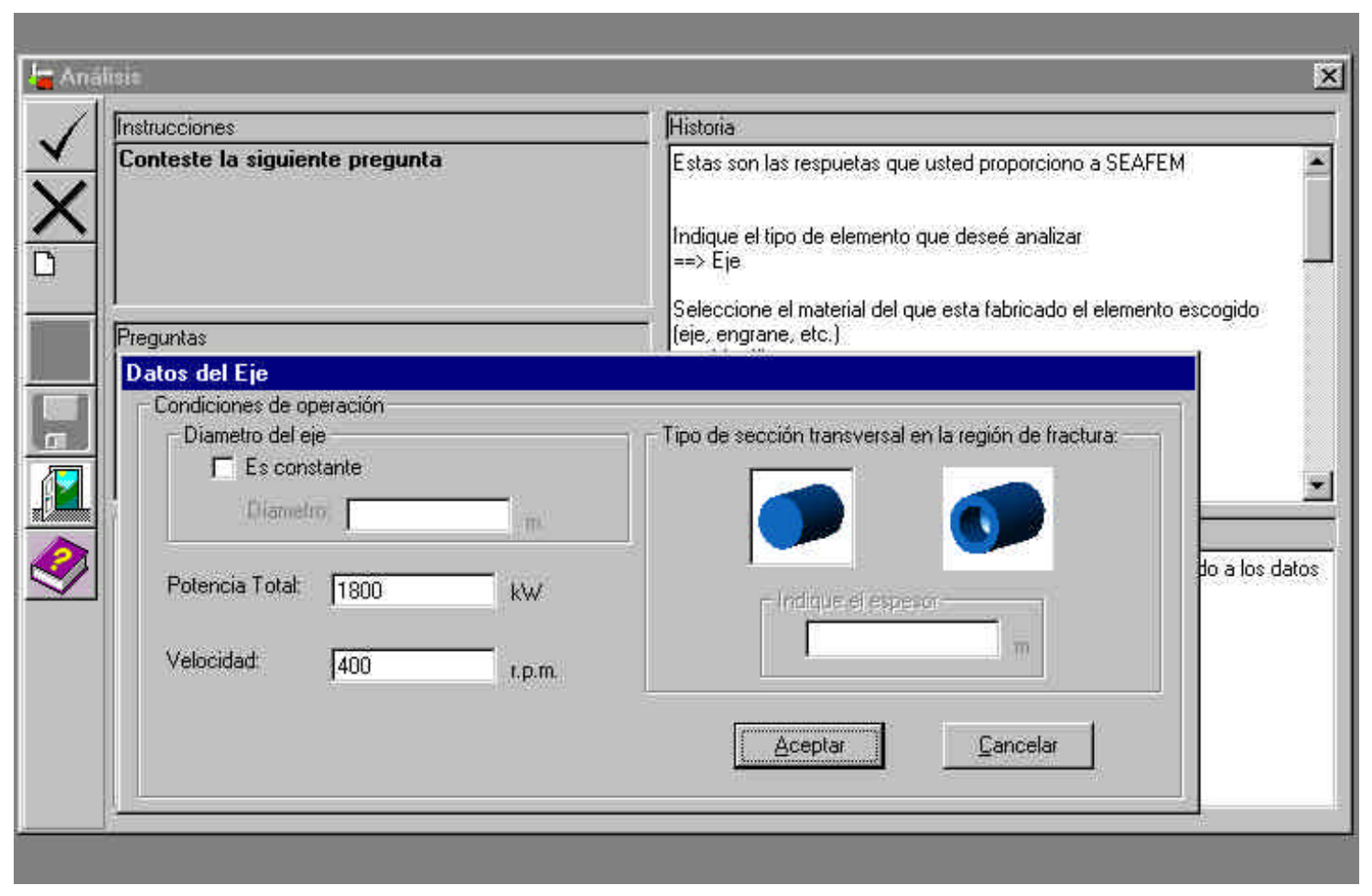

Figura 5. Ventana sobre datos gener ales geométricos y de solicitación del eje

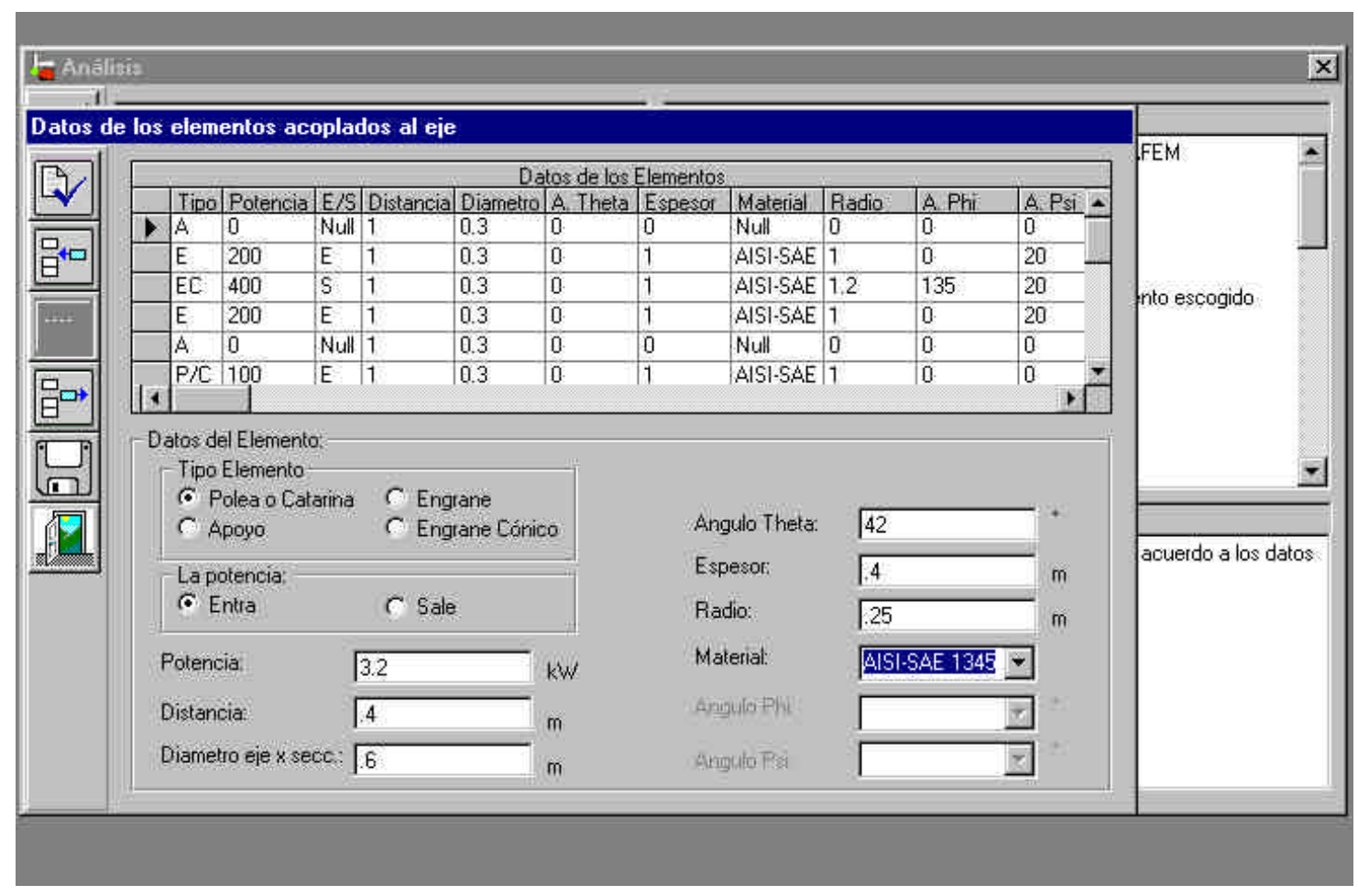

Figura 6. Ventana sobre características apoyos y elementos acoplados al eje 


\section{Operación del módulo de RBC}

La dinámica de operación del módulo de RBC se presenta en el esquema de la figura 7. La secuencia del procedimiento es la siguiente:

1) En una interfase se obtiene toda la información del caso en estudio. El sistema almacena esa información en un vector.

2) El vector es comparado con los vectores de los casos históricos, utilizando medidas de relevancia y la biblioteca de índices.

3) El programa obtiene la similitud y ordena los casos de forma decreciente de acuerdo a la similitud en una tabla, donde también aparece el número de caso. El usuario puede elegir cuál caso desea analizar de entre los diez más semejantes.

4) A través del número del caso histórico, el sistema activa los archivos de descripción del caso y los de imágenes sobre el módulo de explicación.

En la operación del sistema la primer pantalla de captura es la de llaves primarias (Figura 8). Se asignan valores de 1 en el caso de que la característica a evaluar se encuentre presente, en caso contrario, se asigna un -1, en caso de que se tenga duda sobre la existencia de la característica se asigna un "cero". En ésta se definen los criterios más importantes para la búsqueda.

En la figura 9 se presenta la pantalla de clases. Se pueden elegir las clases de atributos para vaciar su información en cualquier orden. Por cada una de las clases que se indican en esta figura se tienen pantallas especificas, que tienen atributos particulares, los cuales asumen los valores de $-1,0$ y 1 .
Una vez que se ha capturado la información de todas las clases, el sistema calcula la similitud y muestra al usuario los casos más semejantes al que está resolviendo (Figura 10). Realizado lo anterior, el usuario puede elegir cualquiera de los casos y cuando lo hace se le presenta la información completa del mismo, incluyendo planteamiento del problema, solución e imágenes descriptivas (Figura 11). Por otro lado, una vez que el usuario ha encontrado una solución exitosa a su problema, puede incorporar el nuevo caso a la base para ir gradualmente incrementando la experiencia del programa al expandir el conocimiento. 


\section{Jacobo-Armendáriz, A. Ortiz-Prado y R. Schouw enaars-Franssens}

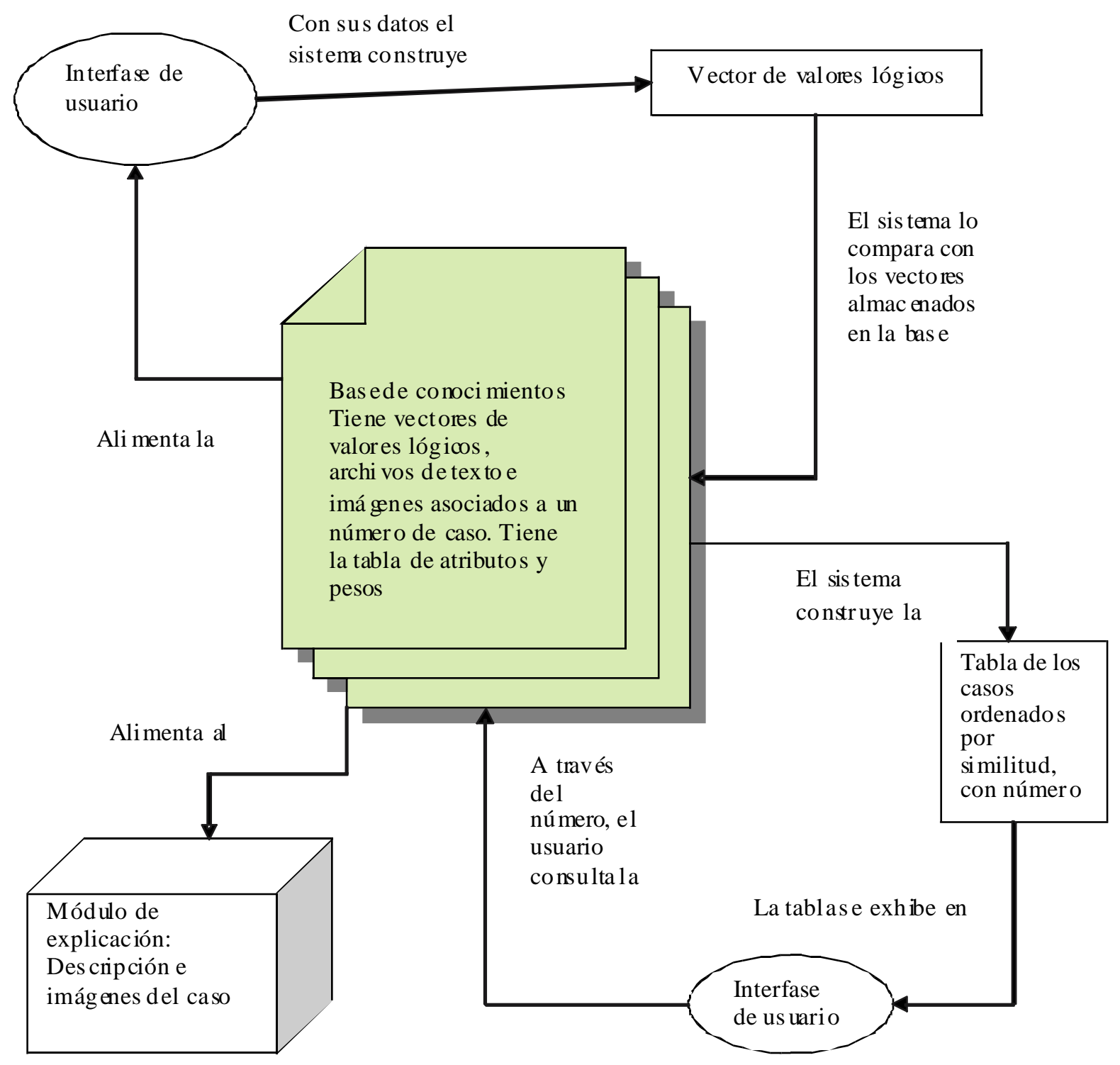

Figura 7. Interacción del sistema en la solución de un caso de AF mediante RBC 
SEAFEM: Herramienta computacional para la determinación de causas de falla en ...

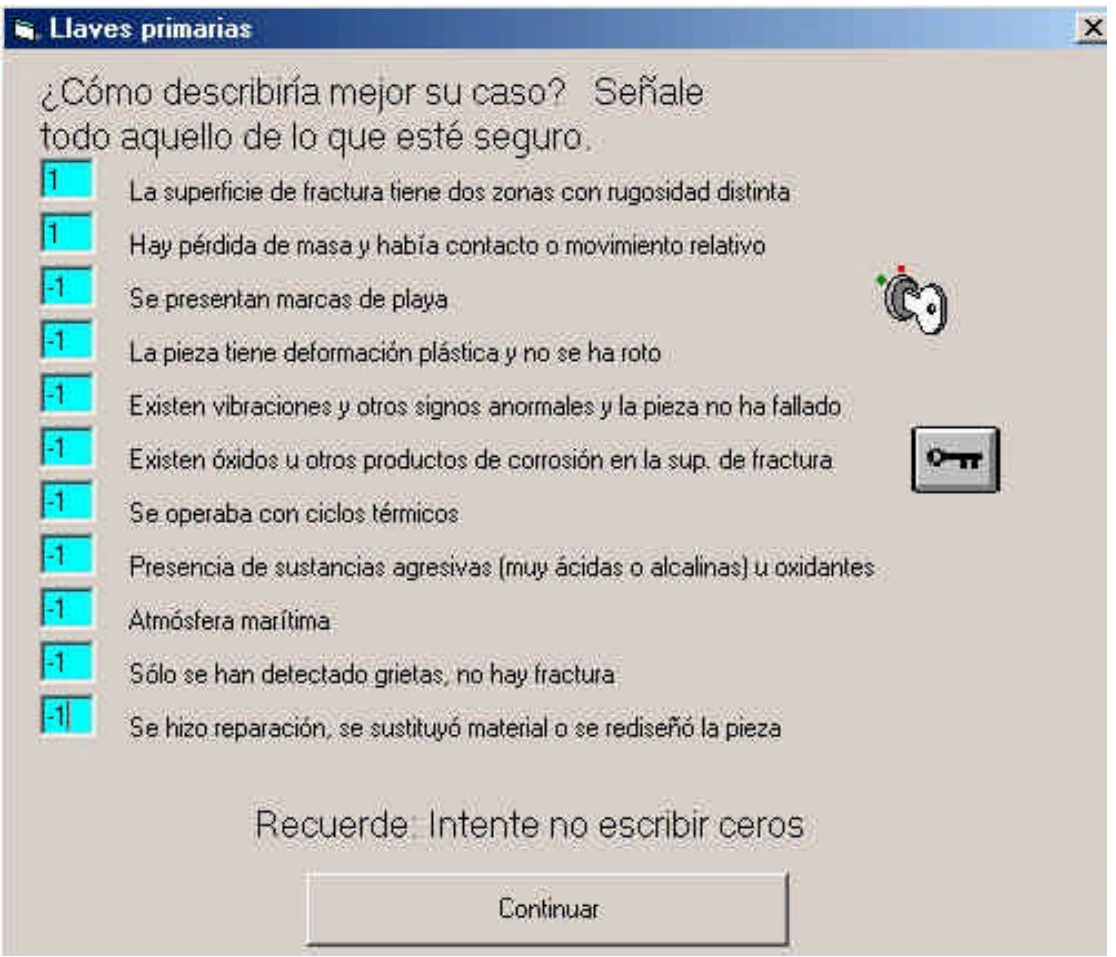

Figura 8. Llaves primarias

\section{E. Clases}
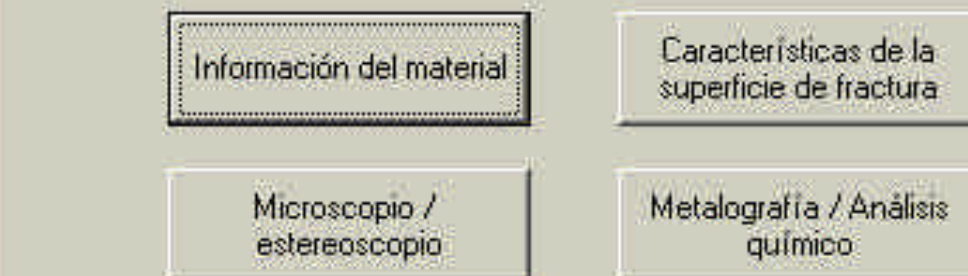
superficie de fractura

estereoscopio

\section{Metalografia / Anălisis quimico}

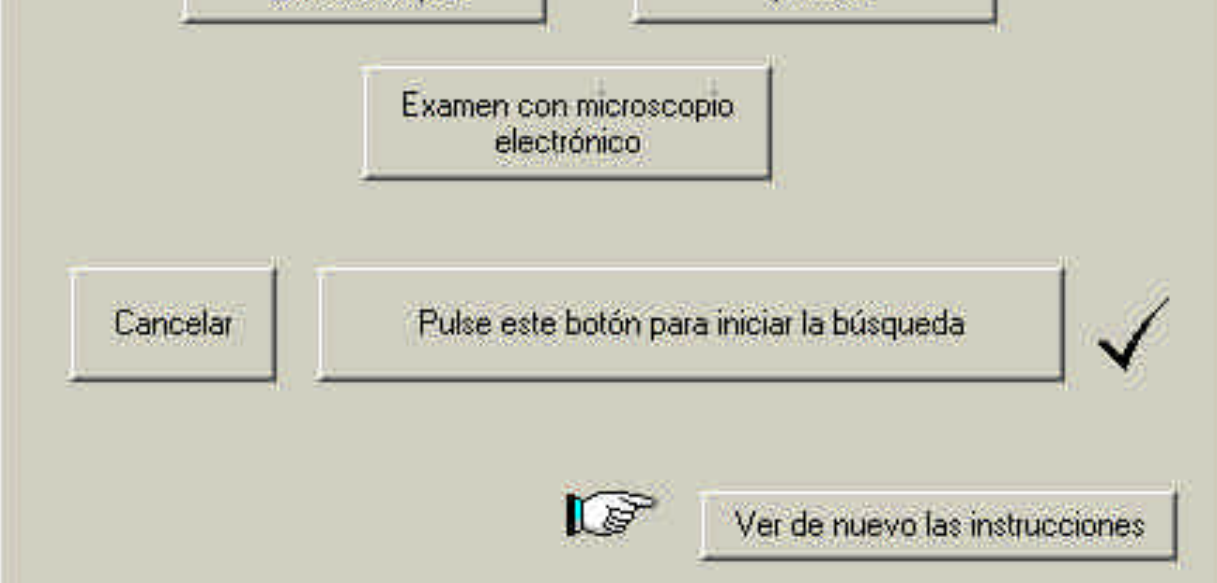

Figura 9. Pantallas de clases 


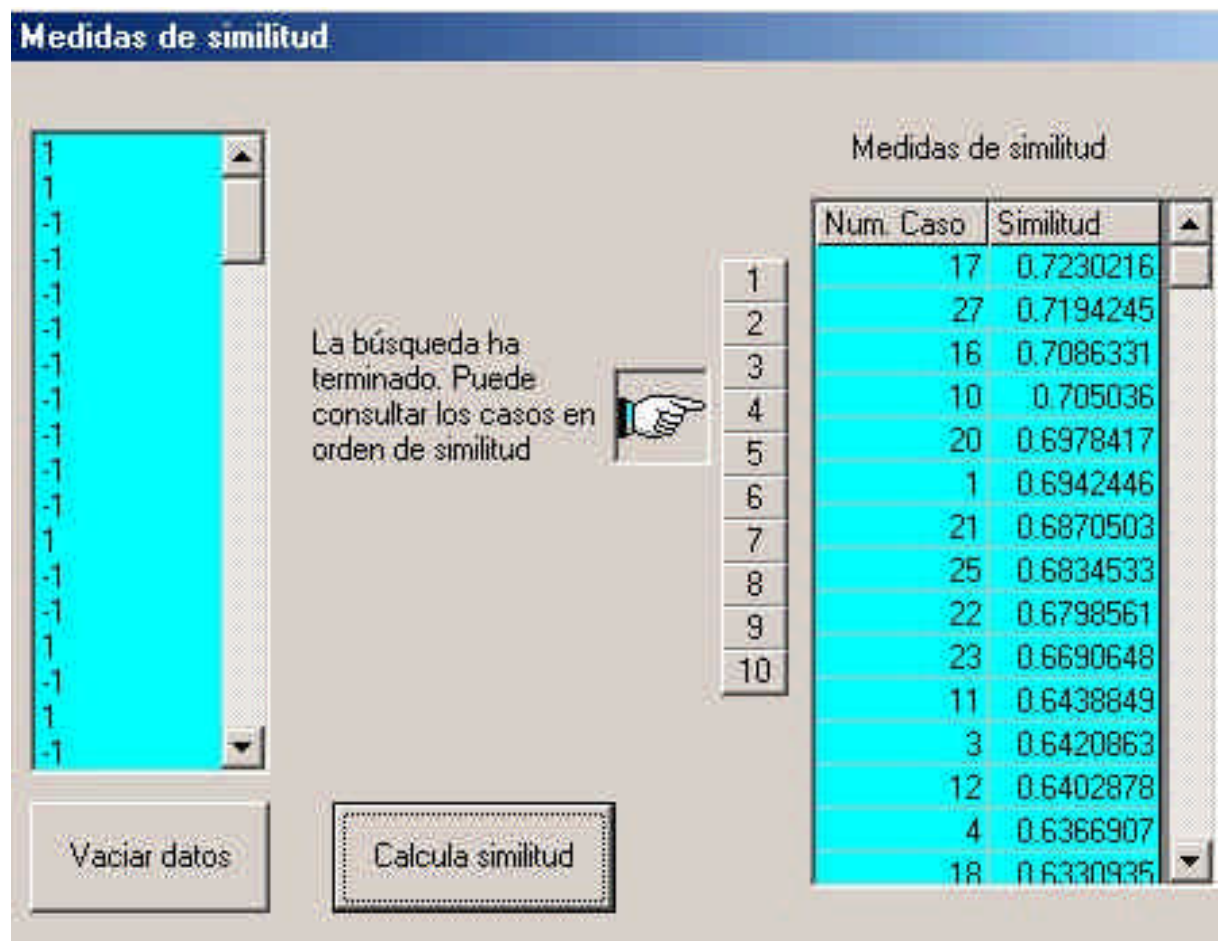

Figura 10. Pantalla de medidas de similitud; luego de barrer toda la base de casos se obtiene la similitud y presentan en orden los mismos

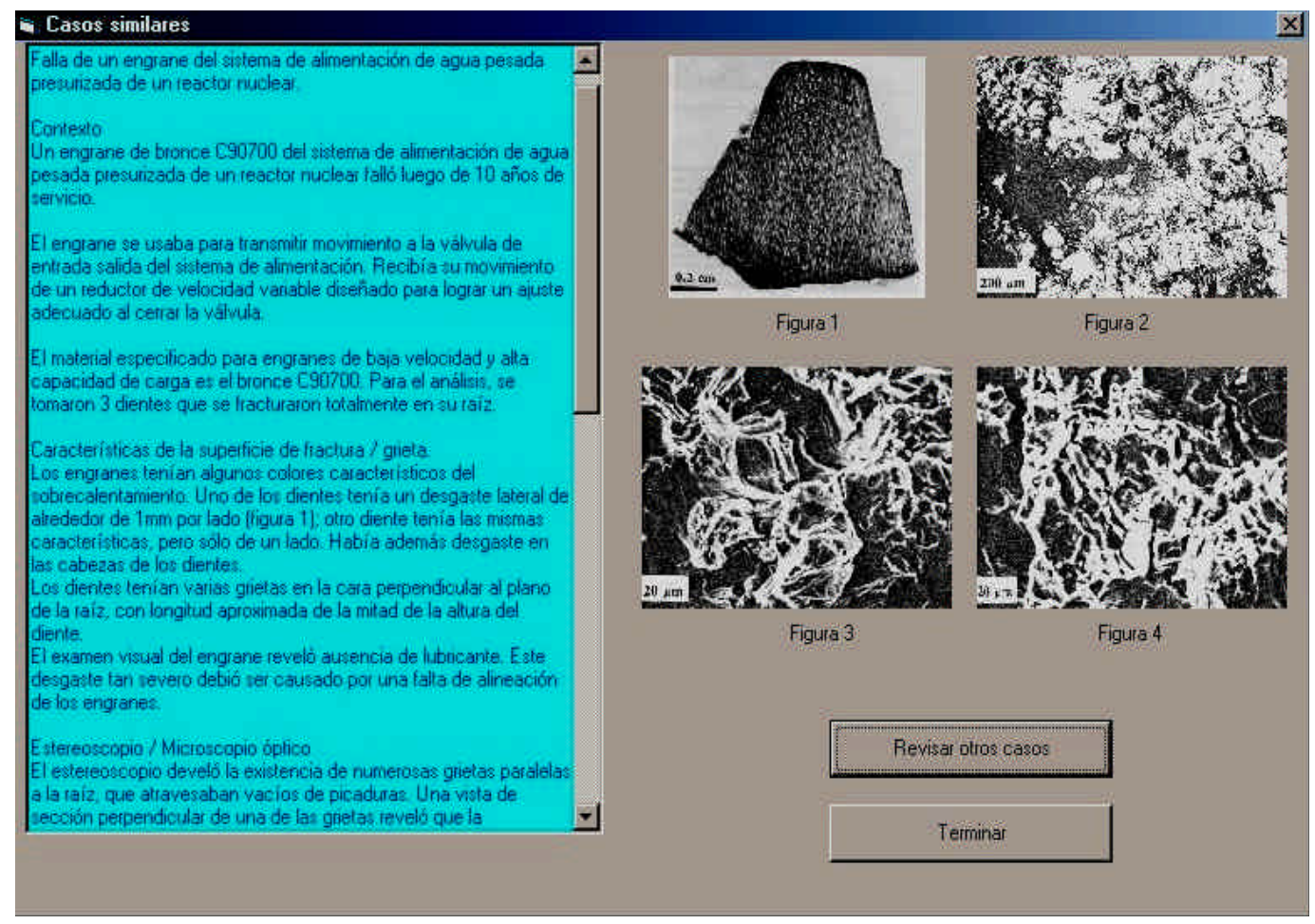

Figura 11. Pantalla de casos similares 


\section{Validación, análisis y discusión de resultados}

Para efectos de validación y verificación se aplicó el sistema en 4 casos, los primeros dos fueron seleccionados del apartado sobre fallas en ejes de ASM (Metals Handbook, 1990). El tercero (ejes) y el cuarto (barras de torsión) corresponden a dos casos que fueron resueltos por el grupo de investigación al que pertenecen los autores (UDIATEM, 2004a, 2004b). Los cuatro casos fueron resueltos por los módulos de RBR y RBC.

En lo que se refiere al módulo de RBR (Jacobo et al., 2005), los resultados tuvieron correspondencia respecto de lo que se indica en la literatura. Una parte importante de los resultados que provee el sistema es el componente explicativo, el cual va describiendo la información de entrada de los casos, en donde se muestran también las causas de la falla, así como su mecanismo.

También, plantea una recomendación para la realización de pruebas de laboratorio (inspección a bajos aumentos, análisis químico, dureza, etc). En algunos casos, la información está incompleta, aún así el sistema brinda soluciones con la información disponible, esto evidentemente reduce el nivel de confianza y debe ser tomado en cuenta por el analista. Con referencia a la identificación de concentradores de esfuerzos mecánicos, las imágenes que se presentan en el sistema mostraron una correspondencia al $100 \%$ con las que aparecen en los casos reportados en la literatura, lo mismo ocurre en el caso de la identificación de los patrones característicos de fracturas. Esto último resulta importante, ya que al introducir la información de entrada al sistema se puede incurrir en errores de apreciación.

Un punto importante a señalar, es que el sistema brinda resultados discretos, esto lo distingue de los casos reportados en la literatura, en donde se da una descripción más a detalle de todo el contexto de la falla y los procedimientos de análisis y solución. Sin embargo, la forma en que se realiza el proceso mediante el sistema, permite que el usuario se capacite y aprenda sobre la manera de resolver problemas de AF.

El módulo de RBC mostró un desempeño satisfactorio (Jacobo et al., 2005), haciendo notar que los criterios más importantes que se observan en cuanto a similitud son el mecanismo de falla en primer término y en segundo, el tipo de elemento. Como se mencionó, el usuario tiene la opción de consultar los 10 casos con mayor similitud, lo cual le permite accesar a un caso en donde se esté manejando el mismo tipo de elemento.

Al resolver los 4 casos por ambos métodos, se observó que se complementan de manera satisfactoria, ya que mientras en uno se aprenden los procedimientos deductivos, en el otro se pueden estudiar casos similares con información in extenso. Todo lo anterior permite que el usuario tenga una mayor comprensión, y por ende, aprendizaje de los problemas planteados.

\section{Conclusiones}

El sistema desarrollado determina las causas de falla de elementos mecánicos metálicos y permite determinar acciones correctivas.

Al manejar dos métodos de razonamiento (basado en reglas y basado en casos), el sistema presentado permite al usuario, por un lado, utilizar y ejercitar sus procesos de razonamiento deductivo, y por otro, el manejo de información estructurada en bases de datos.

La enseñanza del AF se ve beneficiada al contar con una herramienta interactiva, la 


\section{Jacobo-Armendáriz, A. Ortiz-Prado y R. Schouw enaars-Franssens}

cual maneja dos métodos; uno orientado al aprendizaje de los procesos de razonamiento de expertos en AF y el otro que maneja información documentada con descripciónin extenso de casos de fallas. Asimismo, resulta importante el empleo de imágenes y de texto estructurado sobre los diferentes problemas.

El módulo de RBR es una herramienta útil en la detección de los distintos tipos de fractura, genera conclusiones intermedias de las causas que llevaron a la falla y recomienda las pruebas de laboratorio necesarias para validar las conclusiones intermedias. La máquina de inferencia de este módulo, funciona de manera independiente a la interfase, de modo que la base del conocimiento puede ser expandida en el futuro sin alterar el código .

Se puede tener una mayor confiabilidad en las soluciones de un $\mathrm{SE}$ en $\mathrm{AF}$, si se comparan los resultados contra una base de casos históricos.

El desarrollo del proyecto presentado permitió la gestación de una línea de trabajo en torno al desarrollo de sistemas inteligentes para AF de elementos mecánicos, siendo el grupo al que pertenecen los autores, pionero en esta área en la UNAM y en México.

\section{Agradecimientos}

Se agradece a la Dirección General de Asuntos del Personal Académico de la UNAM, por el apoyo económico otorgado a través del proyecto PAPIIT IN 105902. Asimismo, se reconoce el apoyo técnico brindado por los ingenieros Ignacio Cueva, Efraín Ramos y al Biol. Germán Álvarez.

\section{Referencias}

Abou-Ali M., Khamis M. (2003). TIREDDX: An Integrated Intelligent
Defects Diagnostic System for Tire Producction and Service. Expert Systems With Applica tions 24, pp. 247-259.

Adedeji B. (1992). Expert Systems Applications in Engineering and Manufacturing. Prentice Hall.

ASM (1974). Source Book in Failure Analysis. Amer ican Society for Metals.

ASM (1992). Hand book of Failure Anal ysis. ASM inter na tional, USA.

Beckman T. (1991). AI-Expert. The Magazine of Artificial Intelligence in Practice, February.

Brooks C., Choudhury A. (1993). Metallurgical Failure Anal ysis . McGraw-Hill.

Cerrud S., Ortiz A., Jacobo V. y Márquez E. (1998). Propuesta para el desarrollo de un sistema experto en análisis de falla de elementos mecánicos metálicos. Memorias del IV Congreso Anual de la Sociedad Mexicana de Ingeniería Mecánica, Ciudad Juárez, Chih. Octubre.

Cerrud S., Jacobo V., Ortiz A., Quiroz H. y Márquez E. (2000). Adquisición y representación del conocimiento en un sistema experto para análisis de falla. Memorias del VI Congreso Anual de la Sociedad Mexicana de Ingeniería Mecánica, Colima, Colima.

Cerrud S. (2002). Propuesta de metodología para el desarrollo de un sistema experto en análisis de falla de elementos mecánicos metálicos. Tesis de maestría (Ingeniería Mecánica). División de Estudios de Posgrado, Facultad de Ingeniería, UNAM.

Cerrud S., Jacobo V., Ortiz A. y Schouwenaars R. (2002). Análisis de Falla. Facultad de Ingeniería UNAM.

Cerrud S., Jacobo V., Schouwenaars R. y Ortiz A. (2003). Diseño de un modelo para el estudio de riesgo de falla por corrosión en tubería de concreto preesforzado. Memorias del IX Congreso de la Sociedad Mexicana de Ingeniería Mecánica. Veracruz, Veracruz. Septiembre. 
SEAFEM: Herramienta computacional para la determinación de causas de falla en ...

Corrosion Atlas (1991). Elsevier Science, The Netherlands.

Das A. (1996). Metal lurgy of Failure Analysis. Ed. McGraw-Hill.

Graham-Jones P. and Mellor B. (1995a). The Development of a Generic Failure Analysis Expert System Based on CaseBased Reasoning. Southampton Uni -versity.

Graham-Jones P. and Mellor B. (1995b). Expert and Knowledge-Based Systems in Failure Analysis. Engineering Failure Anal ysis 2, pp. 137-149.

Graham-Jones P. and Mellor B. (1997a). Expert Systems in Failure Analysis. Part of the Engineering Materials Failure Series. Southampton, Univer sity U.K.

Graham-Jones P. and Mellor B. (1997b). The Oportunities for the Internet to Assist with Failure Anal ysis. NACE Corro sion.

Graham-Jones P. and Mellor B. (1997c). Issues Involved in Developing a Failure Analysis Expert System For Metallic Materials Using Rule and Case-Based Reasoning. NACE Corro sion.

Heyes A. (1998). Automotive Component Failures. Engineering Failure Analysis 5,2, pp. 129-141.

Jacobo V. et al. (1994). Análisis para el desarrollo de un sistema experto en selección de materiales. Tesis de Licenciatura. Ingeniero Mecánico Electricista (Industrial) Facultad de Ingeniería, UNAM.

Jacobo V. Cerrud S. y Ortiz A. (2000). Prototipo de un sistema experto para el análisis de falla de elementos mecánicos. Memorias del X Congreso Latinoamericano de Investigación de Operaciones, Mexico, DF.

Jacobo V., Cerrud S., Ramírez M. y Ortiz A. (2002). Sistema experto para aná-lisis de falla de ejes. Ingeniería Investigación y Tecnología, 3,3.

Jacobo V., Cerrud S., Ortiz A. y Márquez E. (2004). Sistema experto híbrido para análisis de falla de elementos mecánicos metálicos. Memorias del X Congreso Anual de la Sociedad Mexicana de Ingeniería Mecánica. Querétaro, Qro. Septiembre.

Jacobo V., Ortiz A., Schouwenaars R. y Márquez E. (2005). Sistema experto para análisis de falla de elementos mecánicos metálicos. Verificación y validación. Memorias del XI Congreso Anual de la Sociedad Mexicana de Ingeniería Mecánica, Morelia, Mich.

Jones D. (Editor). (1998). Failure Analisis Case Studies. Elsever Science Ltd.

Kazaz A. (2003). Application of an Expert System on the Fracture Mechanics of Concrete. Arti fi cial Intel li gence Review 19, pp. 177-190.

Komai K., Minoshima K. and Yamasaki N. (1995). Devel op ment of Expert System for Fractography of Envi ron mentally Assisted Cracking, Univer sity of Tasmania.

Kudryavtsev Y., Kleiman J., Trufiakov V. and Mikheev P. (1998). Expert System for Fatigue Assessment and Optimization of Welded Elements. Integ rity Testing Laboratory Inc \& Paton Welding Insti tute.

Lange. G. (1998). Systematic Analysis of Technical Failures. Informationsgesellschaft, Verlag.

Lee R. (2001). Development of an Expert System to Assist Fractographical Analysis. Advanced Systems and Analysis Divi sion, NASA.

Liao T., Zhan Z. and Mount C. (1999a).An Integrated Database and Expert System for Failure Mechanism Identification: Part I- Automated Knowledge Acquisition. Engineering Failure Analysis 6, pp. 387-406.

Liao T., Zhan Z. and Mount C., (1999b). An Integrated Database and Expert Systemfor Failure Mechanism Identification: Part II- The System and Performance Testing. Engineering Failure Analysis 6, pp. 407-421. 


\section{Jacobo-Armendáriz, A. Ortiz-Prado y R. Schouw enaars-Franssens}

Liao T. (2000). A Case-Based Reasoning System for Identifying Failure Mechanisms. Engi neering Appli ca tions of Artificial Intel li gence 13, pp. 199-213.

Liao T. (2004). An Inves ti gation of a Hybrid CBR Method for Failure Mechanisms Identification. Engineering Applications of Artificial Intelligence 17, pp. 123-134.

Menandro F., Moyer E. and Liebowitz H. (1995). An Expert System Approach to Fracture Mechanics. Engineering Fracture Mechanics 50, pp. 631-637.

Metals Handbook (1990). Vol. 11: Failure Analysis and Prevention. ASM Inter national, USA.

Naumann F. (1983). Failure Analysis: Case Histories and Methodology. ASM Verlag GmbH Stuttgart.

Ortiz A. Jacobo V. Cerrud S. y Hernández A. (2003). Análisis de falla de elementos mecánicos metálicos mediante razonamiento basado en casos. Memo- rias del IX Congreso Anual de la Sociedad Mexicana de Ingeniería Mecánica. Veracruz, Veracruz, Septiembre.

Roberge P., Tullmin M. and Trethewey K. (1996). Failure Anal ysis by Case-Based Reasoning. Proceed ings of the Inter national Congress InterCorr.

Roberts C. and Glantz W. (2003). SKF Bearing Detective: Preventing Reoccurring Bearing Failures. SKF Group, 15:39.

Shu-Hsien L. (2005). Expert System Methodologies and Applications - A Decade Review form 1995 to 2004. Expert Systems with Applications 28, pp. 93-103.

UDIATEM (2004a). Análisis de falla de barra de torsión de autobús Volvo. Reporte de circulación restringida, -Volvo Buses de México.

UDIATEM, (2004b). Análisis de falla de semieje trasero DANA. Reporte de circulación restringida,-Inter na tional. 
DOI: http://dx.doi.org/10.22201/fi.25940732e.2007.08n4.021

SEAFEM:Herramienta computacional para la determinación de causas de falla en ...

\section{Semblanza de los autores}

Víctor Hugo Jacobo-Armendáriz Ingeniero mecánico electricista (área de Ing. Industrial) por la Facultad de Ingeniería de la UNAM, en donde también obtuvo los grados de maestro y doctor en ingeniería. Actualmente funge como profesor titular "B" de tiempo completo definitivo en el área de manufactura y materiales, en la propia FI-UNAM. Su línea se ha orientado al análisis de falla, la ciencia de materiales y los sistemas expertos (tema en el cual obtuvo su doctorado). De 10 años a la fecha, ha participado en diversos proyectos y estudios al desarrollo y mejora de métodos de manufactura, corrosión y análisis de falla. Ha dirigido 6 tesis de licenciatura y publicado 2 textos en (análisis de falla, corrosión y protección), más de 5 artículos en congresos internacionales, más de 25 en congresos nacionales y más de 10 en revistas arbitradas. Recibió la Cátedra espe cial SEFI en 2001 y la Antonio Dovalí en 2002.

Armando Ortiz-Prado. Se graduó como ingeniero mecánico electricista (Ing. mecánica) por la Facultad de Ingeniería de la UNAM en 1980, posteriormente obtuvo la maestría y el doctorado en ingeniería mecánica. Es profesor hace 27 años, impartiendo cátedra principalmente en las áreas de procesos de manufactura y ciencia de materiales. En la actualidad, es profesor titular " $\mathrm{C}$ " de tiempo completo definitivo y tutor doctoral de los posgrados de ciencia e ingeniería de materiales y de ingeniería. Sus líneas de investigación son modelado de procesos de conformado mecánico, análisis de falla, comportamiento mecánico de biomateriales y corrosión en equipo electrónico. Ha desarrollado proyectos y estudios para diferentes empresas privadas y entidades gubernamentales, orientados éstos al desarrollo y mejora de métodos de manufactura, desarrollo de materiales, corrosión y análisis de falla; lo cual se traduce en más de 50 estudios y asesorías para la indu stria, 10 proyectos de investigación y desarrollo tecnológico. A la fecha, suma más de 80 tesis de licenciatura concluidas, así como 10 de maestría y una de doctorado. Su experiencia se ha transmitido a través de 6 textos para licenciatura en las áreas de manufactura, materiales y corrosión. Asimismo, su productividad incluye más de 15 artículos en congresos internacionales, más de 50 artículos en congresos nacionales y más de 10 artículos en revistas arbitradas. Fue galardonado por la UNAM con la Distinción Universidad Nacional para Jóvenes Académicos (Docencia en ciencias exactas) en 1989. Recibió la cátedra especial "Mariano Hernández Barrenechea" de Facultad de Ingeniería, UNAM en 1997 y 1998. Su productividad académica y científica ha sido reconocida por la UNAM, a través del otorgamiento del nivel D del PRIDE y por el CONACYT con el nombramiento de Investigador Nacional Nivel I.

Rafael Schouwenaars-Franssens. Obtuvo el grado de maestro en ingeniería de minas en la Universidad de Lovaina, Bélgica y el doctorado en ingeniería mecánica en la FI-UNAM. Ocupa el nivel I en el sistema nacional de investigadores. Durante cuatro años estaba activo como investigador de proyectos industriales, relacionados con la textura cristalográfica en aceros en el Departamento de Metalurgía e Ingeniería de Materiales de la misma universidad. Su trabajo en México lo inició como experto en microscopía electrónica dentro de la Unidad de Investigación y Asistencia Tecnológica en Materiales (UDIATEM). Posteriormente, combinó estas actividades con una carrera de profesor en la Facultad de Ingeniería. En el ámbito tecnológico se dedica al análisis de falla y la optimización de procesos en la indu stria metal-mecánica, con un enfoque espe cial hacia las aleaciones tribológicas dúctiles. Esto lo ha llevado a una serie de estudios científicos relacionados con las propiedades mecánicas de materiales complejos, los cuales han sido publicados en numerosos foros nacionales e internacionales. 